\title{
Seasonal MLT-region nightglow intensities, temperatures, and emission heights at a Southern Hemisphere midlatitude site
}

\author{
Iain M. Reid ${ }^{1,2}$, Andrew J. Spargo ${ }^{2}$, Jonathan M. Woithe ${ }^{1}$, Andrew R. Klekociuk ${ }^{2,3}$, Joel P. Younger ${ }^{1,2}$, and \\ Gulamabas G. Sivjee ${ }^{4}$ \\ ${ }^{1}$ ATRAD Pty Ltd, 20 Phillips St., Thebarton, 5031, Australia \\ ${ }^{2}$ School of Physical Sciences, University of Adelaide, Adelaide 5000, Australia \\ ${ }^{3}$ Antarctica and the Global System, Australian Antarctic Division, Department of the Environment and Energy, Kingston, \\ Tasmania, Australia \\ ${ }^{4}$ Embry Riddle Aeronautical University, Department Physical Sciences, Daytona Beach, FL 32114, USA \\ Correspondence to: Iain M. Reid (ireid@atrad.com.au)
}

Received: 25 January 2017 - Revised: 23 March 2017 - Accepted: 23 March 2017 - Published: 18 April 2017

\begin{abstract}
We consider 5 years of spectrometer measurements of $\mathrm{OH}(6-2)$ and $\mathrm{O}_{2}(0-1)$ airglow emission intensities and temperatures made near Adelaide, Australia $\left(35^{\circ} \mathrm{S}\right.$, $138^{\circ} \mathrm{E}$ ), between September 2001 and August 2006 and compare them with measurements of the same parameters from at the same site using an airglow imager, with the intensities of the $\mathrm{OH}(8-3)$ and $\mathrm{O}\left({ }^{1} \mathrm{~S}\right)$ emissions made with a filter photometer, and with 2 years of Aura MLS (Microwave Limb Sounder) v3.3 temperatures and 4.5 years of TIMED SABER (Thermosphere Ionosphere Mesosphere Energetics and Dynamics Sounding of the Atmosphere using Broadband Emission Radiometry) v2.0 temperatures for the same site. We also consider whether we can recover the actual emission heights from the intercomparison of the ground-based and satellite observations. We find a significant improvement in the correlation between the spectrometer OH and SABER temperatures by interpolating the latter to constant density surfaces determined using a meteor radar.
\end{abstract}

Keywords. Atmospheric composition and structure (airglow and aurora)

\section{Introduction}

Observations of $\mathrm{OH}$ and $\mathrm{O}_{2}$ rotational temperatures provide a relatively simple method of routinely measuring temperatures in the atmosphere at altitudes near 87 and $94 \mathrm{~km}$, respectively, at night. The $\mathrm{OH}$ emission in particular has been extensively studied using ground-based instruments (e.g. Se- menov et al., 2013) and using satellite-based instruments (e.g. Xu et al., 2010, 2012) and has been modelled in some detail (e.g. Grygalashvyly et al., 2014; Sonnemann et al., 2015). There are rather more ground-based observational sites in the Northern Hemisphere (NH) than the Southern Hemisphere (SH). For example, Semenov et al. (2013) summarise $27 \mathrm{NH}$ and $9 \mathrm{SH}$ sites, which includes some historical locations. Reisin et al. (2014) summarise contemporary sites in the Network for the Detection of Mesospheric Change (NDMC) and include $13 \mathrm{NH}$ and $6 \mathrm{SH}$ sites. The addition of a new ground-based 5-year $\mathrm{OH}(6-2)$ and $\mathrm{O}_{2}(0-1)$ rotational temperature data set from another $\mathrm{SH}$ site is therefore useful.

Routine observations of $\mathrm{OH}(6-2)$ and $\mathrm{O}_{2}(0-1)$ rotational temperatures began in 2001 at the Buckland Park (BP) field site located near Adelaide $\left(35^{\circ} \mathrm{S}, 138^{\circ} \mathrm{E}\right)$, Australia, using a Czerny-Turner spectrometer, although some limited measurements of the $\mathrm{OH}(6-2)$ emission were made earlier using a similar instrument, prior to it being relocated to Antarctica (Hobbs et al., 1996). Detailed descriptions of the system used in the present study, its automated mode of operations, and its data acquisition facilities have been reported by Sivjee and Shen (1997).

In this paper, we describe the results from the spectrometer for the 5-year period from September 2001 until August 2006, when it ceased operation. We compare the spectrometer $\mathrm{OH}(6-2)$ and $\mathrm{O}_{2}(0-1)$ temperatures and emission intensity results with $\mathrm{OH}(8-3)$ and $\mathrm{O}\left({ }^{1} \mathrm{~S}\right)$ emission intensities from a three-field photometer (3FP) (see, e.g., Reid et 
al., 2014) that has operated at the site since 1995 and with $\mathrm{OH}(6-2)$ and $\mathrm{O}_{2}(0-1)$ temperatures and emission intensities from an imager with a temperature capability that has been operated at the site since 2001 (see, e.g., Hecht et al., 1997) by Aerospace Corporation. We also compare the spectrometer results with v3.3 temperatures from the Microwave Limb Sounder (MLS) instrument on the Aura satellite for the period between 8 August 2004 and 1 August 2006 and with v2.0 temperatures from the Sounding of the Atmosphere using Broadband Emission Radiometry (SABER) instrument on board the Thermosphere Ionosphere Mesosphere Energetics and Dynamics (TIMED) satellite for the period between 26 January 2002 and 1 August 2006. The MLS data were quality-screened according to criteria recommended by Livesey et al. (2011). In this study, we assume that the $\mathrm{OH}(6-2)$ and $\mathrm{O}_{2}(0-1)$ rotational level populations are in local thermodynamic equilibrium, which seems a fair assumption based on the agreement with other techniques, but we do note the work of Noll et al. (2016), which indicates that some care may be required in the interpretation of high-altitude $\mathrm{OH}$ rotational temperature results for high and even $v^{\prime}$.

A detailed interpretation of ground-based passive airglow observations is often limited by the lack of information about the actual emission height, which may change with time of day and time of year. Younger et al. (2015) have described a new technique for determining the height of a constant density surface at altitudes of $78-85 \mathrm{~km}$ using meteor radar data. In this work, we compare 1 year of spectrometer $\mathrm{OH}(6-2)$ and SABER temperatures using the assumption that the $\mathrm{OH}(6-2)$ emission height follows a constant density surface using meteor-radar-derived neutral density measurements. This allows us to gain a better understanding of this aspect of our observations and significantly improves the correlation between the two observations.

\section{Equipment}

The BP field site is home to several instruments for investigating the atmosphere. In addition to the Czerny-Turner spectrometer and meteor radar, which we describe below, the instruments of most interest to this work are the 3FP and the Aerospace Imager. The 3FP has been described by Woithe (2000), Ding et al. (2004), Reid and Woithe (2005, 2007), and Reid et al. (2014). It measures the intensity of the $\mathrm{O}\left({ }^{1} \mathrm{~S}\right) 558 \mathrm{~nm}$ and $\mathrm{OH}(8-3) 730 \mathrm{~nm}$ airglow emission every minute at night, during moon-free cloudless periods. The Aerospace imager is described by Hecht et al. (1994) and is of particular interest here because of the work of Gelinas et al. (2008), hereinafter G08, who describe observations made using the imager of $\mathrm{O}_{2}(0,1)$ and $\mathrm{OH}(6,2)$ intensity and temperatures made at BP and Alice Springs $\left(23^{\circ} 48^{\prime} \mathrm{S}\right.$, $133^{\circ} 53^{\prime} \mathrm{E}$ ) during the period from 2002 to 2005 .

\subsection{Czerny-Turner spectrometer}

The spectrometer is a high-throughput, modified CzernyTurner spectrometer fitted with long, Fastie-type, curved entrance slits. The detector is a $1024 \times 1024$ Peltier and water-cooled charge-coupled device (CCD) coupled to large aperture $f / 1.2$ lenses. More detail is given in Sivjee and Shen (1997). The instrument's wavelength and intensity response were calibrated using a krypton reference spectrum and a reference black body emitter. The first calibration occurred in December 2000 at the commissioning, and the grating was reset on 14 December 2001 when a new calibration was performed. This calibration was then used until the instrument was decommissioned due to an acquisition system hardware failure in 2007. Before any data analysis was carried out, a dark image was subtracted from a data image to remove intensity contributions from instrument noise. Generally, the dark image was recorded once an hour during data acquisition.

\subsubsection{OH temperatures}

$\mathrm{OH}$ temperature estimates were calculated using the standard "ratio of lines" method from the (6-2) OH band. The J constants for each OH line were obtained from Mies (1974), the Einstein A coefficients for each $\mathrm{OH}$ line from Langhoff et al. (1986), the rotational terms for each $\mathrm{OH}$ transition from Coxon and Foster (1982), and the nominal centre wavelengths (in $\mathrm{nm}$ ) of each transition $\mathrm{OH}$ line emission were obtained from Greet et al. (1998).

Due to very low intensity, the P1(6) and P1(7) lines proved too difficult to definitively characterise in general, so they (and temperature estimates based on them) were omitted from the process. During the analysis, it was also observed that jitter on the P1(5) line due to sampling resolution and low intensity was unacceptably high compared to P1(2), P1(3), and P1(4) and that consequently temperatures calculated using P1(5) often differed wildly from the others. As a result, the "average" $\mathrm{OH}$ temperature uses the temperatures derived from the P1(2): $\mathrm{P} 1(3)$ and $\mathrm{P} 1(2)$ : $\mathrm{P} 1(4)$ ratios.

Two different methods were used to estimate the intensity of the $\mathrm{OH}$ lines. The simplest, referred to as the "height" method, used the peak's maximum recorded value. The alternative, dubbed the "intensity" method, used an integrated intensity under the peak. Both methods yield similar results although the height method may be slightly better if the spectrum is a little noisy. The main problem with the intensity method is that it is hard to positively identify the integration bounds at times due to the limited pixel resolution relative to the peak widths, and this can lead to integration inaccuracies.

\subsection{2 $\mathrm{O}_{2}$ temperatures}

Unlike the $\mathrm{OH}$ temperatures there is no analytical method for calculating temperatures from the $\mathrm{O}_{2}$ band. Consequently, 
one must take the recorded spectrum and compare it against a temperature-dependent model spectrum. The temperature which gives a model which is a best fit for the recorded spectrum is deemed to be the $\mathrm{O}_{2}$ temperature. In the case of the spectrometer data, there is considerable difficulty in carrying out this process because the shape of the $\mathrm{O}_{2}$ band emission often differs from that of the model. This can cause the software to converge on a local best fit which may not be accurate. The practical result of this is a temperature time series which is much noisier than that produced from the $\mathrm{OH}$ analysis. The model spectrum used here is based on Krassovsky et al. (1962). Both the "integrated intensity" and "peak height" properties were used separately to compare the model and recorded spectrum. The peak height results tended to be the better of the two due to difficulties in identifying equivalent integration bounds in the spectra, particularly in the presence of noise in the recorded spectrum.

\subsection{Meteor radar}

The meteor radar used in this work is described by Holdsworth et al. (2004a). It is an ATRAD meteor detection radar (MDR) and operated at Buckland Park between 16 July 2002 and 25 January 2004 before being relocated to Darwin in northern Australia. This radar operates at a frequency of $33.2 \mathrm{MHz}$, with a peak power of $7.5 \mathrm{~kW}$, has one "all-sky" transmit antenna, and uses a five-antenna interferometer on reception to detect meteor echoes in the 70 to $110 \mathrm{~km}$ height range. For the observations we discuss here, typical daily height-resolvable underdense meteor counts at BP varied between 9000 and 14000 per day over the year, and usable winds were determined between heights of 75 and $100 \mathrm{~km}$. A $55 \mathrm{MHz}$ meteor radar similar to that described by Reid et al. (2006) commenced operation at BP at the beginning of 2006, but the spectrometer ceased operation soon after, and there are limited coincident measurements from the two instruments.

Note that we do not attempt to derive temperatures from the meteor radar measured diffusion coefficients here, as for example, described in Holdsworth et al. (2006), as there are significant limitations in this approach (see Lee et al., 2013; Younger et al., 2014). However, Lee et al. (2016) have described a new method of estimating temperatures near the mesopause region using meteor radar observations by calibrating their meteor radar against Aura MLS temperatures. This approach looks promising and has some similarities to the approach we describe below in Sect. 4.3.1.

\subsection{Aura MLS and TIMED SABER temperatures}

To further investigate our temperature results, we considered Aura MLS and TIMED SABER observations. Two important aspects of the satellite measurements to be considered in our comparisons are the vertical resolution and the known bias. The vertical resolution (the averaging kernel width) of the
MLS at $0.46 \mathrm{~Pa}$ is about $14-15 \mathrm{~km}$, and the bias is cold by up to $2 \mathrm{~K}$ (Schwartz et al., 2008). The vertical resolution of SABER in the mesopause region is superior at about $2 \mathrm{~km}$ (Remsberg et al., 2003), and this motivates our use of these measurements in preference to the Aura MLS measurements in Sect. 4.3.2 below.

We accepted satellite measurements within a $500 \mathrm{~km}$ radius of Buckland Park and a time difference for the satellite and ground-based measurements of $30 \mathrm{~min}$ (that is, satellite measurements were only used if they are preceded or followed by a ground-based measurement within $30 \mathrm{~min}$ ). The latter was based on the findings of French and Mulligan (2010). However, we do note that in their study, no substantial change in bias between satellite and ground-based measurements was detected when the time difference between ground and satellite observations was varied between $15 \mathrm{~min}$ and $8 \mathrm{~h}$.

Initially, we applied a Gaussian weighting kernel to the satellite-derived temperatures as per empirically determined weighting functions for the $\mathrm{OH}(6-2)$ (Baker and Stair, 1988) and the $\mathrm{O}_{2}(0-1)$ (McDade et al., 1998) emissions. We later refined this approach to better determine the actual emission heights, and this is discussed in Sect. 4 below.

\section{Results}

\subsection{Spectrometer}

Figures 1 and 2 show the temperatures and intensities through the night and through the year for the $\mathrm{OH}$ and $\mathrm{O}_{2}$ emissions, respectively. Here we have used a superposed year to reduce the noise in these images. Inspection of these figures indicates that the $\mathrm{OH}$ temperatures are clearly less noisy than the $\mathrm{O}_{2}$ temperatures, and a dominant annual oscillation $(\mathrm{AO})$ is evident. The variation of the $\mathrm{O}_{2}$ is harder to determine, but upon further inspection, a semi-annual oscillation $(\mathrm{SAO})$ is discernible.

In the $\mathrm{OH}$ temperatures, minimum temperatures are observed in summer, with a general increase in temperature between the autumnal and vernal equinoxes. During this period, the temperatures are greatest at dawn and dusk. There is a tendency for the temperature to be greatest at equinox, resulting in a semi-annual variation in temperature, which is strongest late in the night, although there is a mid-winter maximum present as well. The $\mathrm{OH}$ intensity tends to be a minimum in the middle of the night throughout the year, with a tendency to a maximum around dusk. There is a general brightening between day 120 and day 250 , but with a 30 to 40-day periodicity also evident during this interval.

In the $\mathrm{O}_{2}$ temperatures, there is a general increase in temperature at the time of the autumnal (March) equinox, with the highest temperatures towards the end of the night at this time. There is a similar but less dramatic increase beginning around the time of the spring equinox. The $\mathrm{O}_{2}$ intensity 

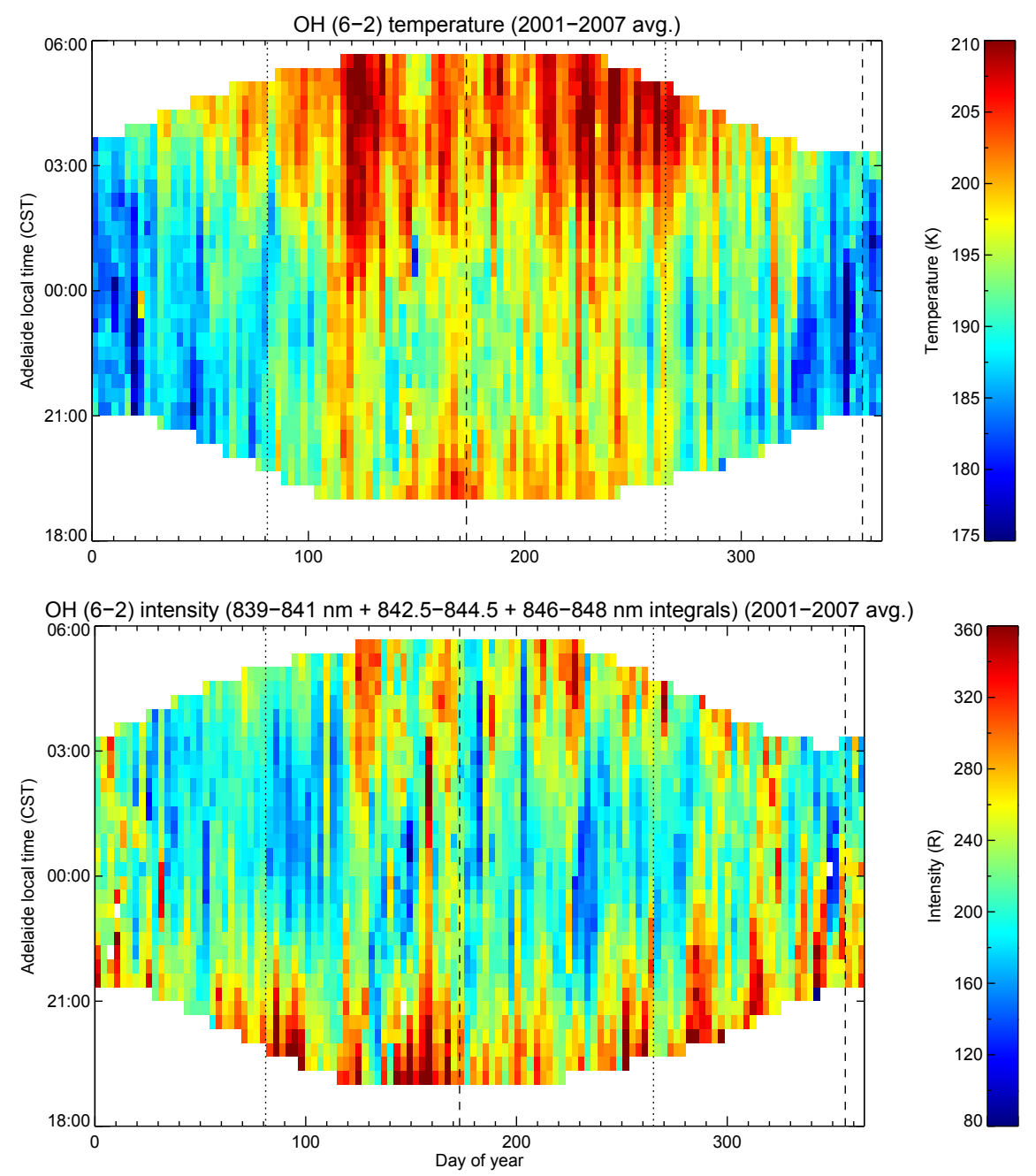

Figure 1. Top: the $\mathrm{OH}(6-2)$ temperature plotted as a function of time of day and time of year for a superposed year. The equinoxes are indicated by dotted lines, the solstices by dashed lines. Minimum temperatures are observed in summer, with a general increase in temperature between the equinoxes. During this period, the temperatures are greatest at dawn and dusk. There is a tendency for the temperature to be greatest between the autumnal equinox and the vernal equinox, with a semi-annual variation in temperature, which is strongest late in the night, although there is a mid-winter maximum present as well. Bottom: as for top panel but for the OH(6-2) emission intensity.

shows a brightening at the equinoxes, particularly later in the night, with the vernal equinox being the brightest part of the year throughout the night.

To quantify the variation of the temperature and intensity data through the night, we follow Reid et al. (2014) and divide the period between 18:00 and 06:00 LT into four $3 \mathrm{~h}$ blocks of data. We then analyse each $3 \mathrm{~h}$ data block using a Lomb-Scargle periodogram to determine the dominant periods present. The significant periods identified in the Lomb periodograms are then used in a harmonic analysis to determine the mean amplitudes and phases of these periods through the period of observation and to estimate the geophysical variation through the night. We also calculate the Lomb-Scargle periodogram for the entire night.

This analysis indicates that $\mathrm{OH}$ temperatures are dominated by an annual oscillation (AO), while in the $\mathrm{O}_{2}$ tem- peratures, the semi-annual oscillation (SAO) dominates. In the $\mathrm{OH}$ temperature Lomb spectra, there are also significant peaks near the SAO and AO periods in the nightly mean, with the SAO peak only appearing at a significant level in the second half of the night. There is a significant peak at the terannual oscillation (TAO) period in the first $3 \mathrm{~h}$ block of the night. In the $\mathrm{O}_{2}$ temperature Lomb spectra, the nightly mean includes significant peaks near the $\mathrm{SAO}$ and $\mathrm{AO}$ periods. There is power at the TAO and quasi-biennial oscillation (QBO) periods, but not at a $99 \%$ significance level. While the QBO is not significant at the $99 \%$ level, we note that QBO-related variations have been repeatedly found in the mesosphere-lower thermosphere (MLT) region in a number of different parameters including tidal wind amplitudes (Xu et al., 2009) and constituent abundances (Zhu et al., 2015). We have also discussed the QBO and quasi-terannual oscilla- 

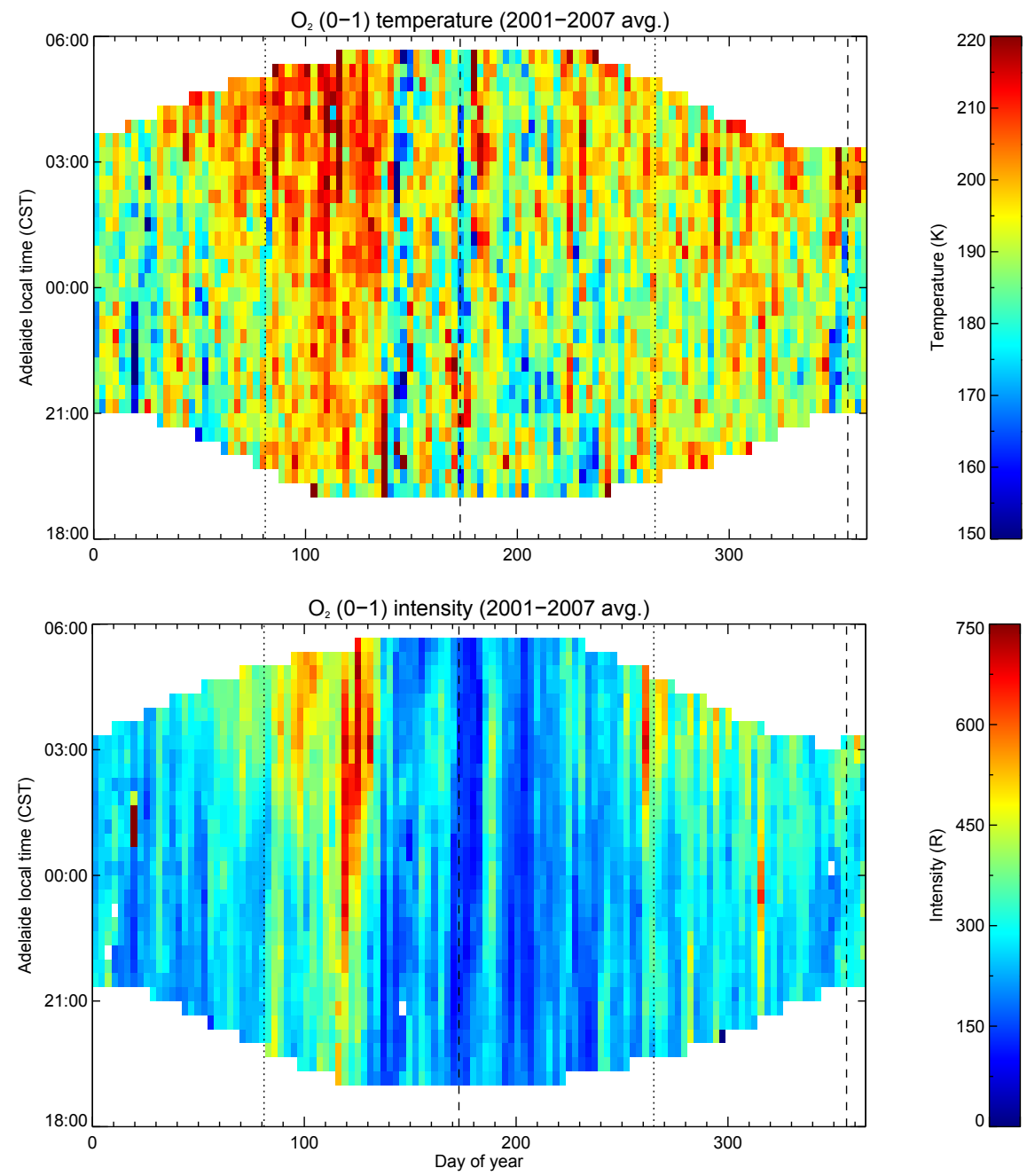

Figure 2. Top: the $\mathrm{O}_{2}(0-1)$ temperature plotted as a function of time of day and time of year for a superposed year. The equinoxes are indicated by dotted lines, the solstices by dashed lines. There is a general increase in temperature at the time of the autumnal equinox, with the highest temperatures towards the end of the night at this time. There is a similar but less dramatic increase beginning around the time of the spring equinox. Bottom: as for top panel but for the $\mathrm{O}_{2}(0-1)$ emission intensity.

tion (QTO) previously in our analysis of long-term measurements of the intensity of the $\mathrm{O}\left({ }^{1} \mathrm{~S}\right)$ and $\mathrm{OH}(8-3)$ nightglow intensity at Adelaide (Reid et al., 2014).

When the composite years for the four $3 \mathrm{~h}$ blocks are examined for the nightly $\mathrm{OH}$ variation, we see a change from a predominately annual variation at the beginning of the night to an annual variation with a semi-annual variation superposed on it. In the case of $\mathrm{O}_{2}$, the temperature variation is generally noisy, but a semi-annual periodicity dominates and strengthens through the night. These variations likely suggest an interaction between tides and the SAO and AO. For example, recent work by Jones Jr. et al. (2017), who used the thermosphere-ionosphere-mesosphere electrodynamics general circulation model (TIME-GCM) to investigate the Thermospheric SAO in density, found that the SAO in the concentration of atomic oxygen in the MLT is forced by non- linear, resolved-scale variations in the advective, net tidal, and diffusive transport of $\mathrm{O}$. This is also consistent with our analysis of the variation of the intensity of the $\mathrm{O}\left({ }^{1} \mathrm{~S}\right)$ and $\mathrm{OH}(8-3)$ nightglow through the night at Adelaide and the local time dependence of amplitude of the SAO and $\mathrm{AO}$ in those emissions (Reid et al., 2014).

Only the AO and SAO are significant at the $99 \%$ level through the entire night, and our results for harmonic fits to the entire observational period for these periods are summarised quantitatively in Table 1 . In the $\mathrm{OH}$, the SAO maximises in the autumn and the $\mathrm{AO}$ in the winter. The $\mathrm{SAO}$ takes a value of $2.1 \mathrm{~K}$ and the $\mathrm{AO}$ a value of $6.6 \mathrm{~K}$. In the case of the $\mathrm{O}_{2}$ temperatures, both the $\mathrm{SAO}$ and $\mathrm{AO}$ maximise in the autumn, with the SAO dominant at $5.1 \mathrm{~K}$, about twice the magnitude of the $\mathrm{AO}$ at $2.6 \mathrm{~K}$. We do note here that the mean and uncertainty in each component in the fit to the nightly 
Table 1. Results of the harmonic fits to the spectrometer $\mathrm{OH}(6-2)$ and $\mathrm{O}_{2}(0-1)$ rotational temperature time series for the entire observational period (September 2001 until August 2006). Phase indicates the first maximum after 1 January. Amplitudes of the AO and SAO are given both relative to the mean temperature and in Kelvin.

\begin{tabular}{lrrr|rr}
\hline \multicolumn{5}{c}{$\mathrm{OH}(6-2)$ and $\mathrm{O}_{2}(0-1)$ temperatures (Sep 2001-Aug 2006) } \\
\hline Emission & Mean $(\mathrm{K})$ & \multicolumn{2}{c}{ AO } & Amplitude (K) & Phase (days) \\
\cline { 3 - 6 } & & Amplitude (K) & Phase (days) & Am \\
\cline { 3 - 6 } & & $3.44 \pm 0.32 \%$ & $184 \pm 4$ & $1.10 \pm 0.69 \%$ & $88 \pm 7$ \\
$\mathrm{OH}(\sim 87 \mathrm{~km})$ & $192 \mathrm{~K}$ & $6.60 \pm 0.61 \mathrm{~K}$ & $3 \mathrm{Jul}($ winter) & $2.11 \pm 1.32 \mathrm{~K}$ & 29 Mar (autumn) \\
& & $1.27 \pm 0.44 \%$ & $130 \pm 22$ & $2.51 \pm 0.63 \%$ & $107 \pm 5$ \\
$\mathrm{O}_{2}(\sim 94 \mathrm{~km})$ & $201 \mathrm{~K}$ & $2.56 \pm 0.89 \mathrm{~K}$ & 10 May (autumn) & $5.05 \pm 1.27 \mathrm{~K}$ & 17 Apr (autumn) \\
& & &
\end{tabular}

mean agree with the average mean and uncertainty of the amplitudes and phases of those components calculated from the vector means of their amplitudes and phases for the three $4 \mathrm{~h}$ blocks. This indicates that the nightly means are representative in that the uncertainties capture the variation through the night.

To further examine the variation of the harmonic components through time, we applied a wavelet spectral analysis to the time series of the 30-day average temperatures (Torrence and Compo, 1998). The results are shown in Fig. 3 (bottom panel; as for Fig. 3 (top panel), but for the $\mathrm{O}_{2}(0-1)$ temperatures). The SAO is the dominant periodicity in this times series, with more power in the $\mathrm{AO}$ later in the observational period. There is power in the wavelet spectrum at the period of the QBO, particularly after 2003, but not at a significant level when averaged over the entire observational period. The top panel shows the wavelet power spectrum for the $\mathrm{OH}$ temperature, along with the time series of 30-day averaged values and their standard deviations and the corresponding Lomb periodogram. The time series is dominated by the AO, which is consistent across the observational period in amplitude and phase. The SAO is present in the second half of the observational period, and the QBO is at its centre. In the lower panel, the $\mathrm{O}_{2}$ temperatures show a dominant $\mathrm{SAO}$, with more power in the $\mathrm{AO}$ later in the observational period. There is power in the wavelet spectrum across the period of observation for the QBO, but not at a significant level.

Figure 4 shows the results of a fit of the AO and SAO only for the $\mathrm{OH}(6-2)$ and $\mathrm{O}_{2}(0-1)$ temperatures and intensities. In the case of the $\mathrm{OH}$, there is general agreement in form, with a dominant $\mathrm{AO}$ with maxima mid-year, that is, in winter. In the case of the $\mathrm{O}_{2}$, there is stronger agreement in form, in this case, a dominant SAO, maximising at the equinoxes. Reid et al. (2014) considered a long series of observations of the $\mathrm{OH}(8-3)$ and $\mathrm{O}\left({ }^{1} \mathrm{~S}\right)$ intensities made at Buckland Park, and shown on these plots are the 3FP $\mathrm{OH}(8-3)$ and $\mathrm{O}\left({ }^{1} \mathrm{~S}\right)$ intensities from their work corresponding to the same observational period. The agreement in form is good in the case of the $\mathrm{OH}$ results and strong in the case of the $\mathrm{O}_{2}(0-1)$ and $\mathrm{O}\left({ }^{1} \mathrm{~S}\right)$ results.

\subsection{Satellite temperatures}

Table 2 gives a summary of the spectrometer $\mathrm{OH}(6-2)$ and $\mathrm{O}_{2}(0-1)$ mean temperatures compared to the Aura MLS mean temperatures using the coincidence criteria described above. We have weighted the measurements with simple Gaussian functions based on Baker and Stair (1988) for the $\mathrm{OH}(6-2)$ emission and McDade (1998) for the $\mathrm{O}_{2}(0-1)$ emission. We have also weighted the spectrometer $\mathrm{OH}$ results with the SABER 1.6 and $2.0 \mu \mathrm{m} \mathrm{OH}$ volume emission rates (VERs). The uncertainty in the mean in this table corresponds to the standard deviations of the samples.

\subsubsection{Aura MLS v3.3 temperatures}

The MLS data have been selected according to the v3.3 status, quality, threshold, and convergence values recommended by the MLS Science Team (Livesey et al., 2011). The Aura MLS mean temperatures weighted according to the estimated $\mathrm{OH}(6-2)$ profile shown in Table 2 are lower than the spectrometer mean, with a difference of $7.5 \mathrm{~K}$, but the results agree to within the experimental error. There is generally good agreement between the amplitudes and phases of the $\mathrm{AO}$ as measured by the two instruments, but not to within the experimental error for the SAO. We have included the temperatures of the Aura MLS corresponding to the $0.46 \mathrm{~Pa}$ level in this table, and these agree with the spectrometer observations to within the experimental error for the mean, the $\mathrm{AO}$, and the SAO. We will further discuss the significance of this below.

The $\mathrm{O}_{2}(0-1)$ mean temperature from the spectrometer is significantly higher than those in the Aura MLS measurements weighted in altitude by the estimated $\mathrm{O}_{2}(0-1)$ profile specified in McDade (1998), and it is clearly biased high. The AO amplitudes agree to within the experimental error, but the phases do not. The SAO amplitudes and phases agree to within the experimental error. We do note that Aura MLS retrievals at pressures of less than $0.1 \mathrm{~Pa}$ are not suitable for scientific use. This should be noted in the comparisons of the MLS with $\mathrm{O}_{2}$ temperatures shown in Table 2. 
Table 2. Comparison between coincident Aura MLS and TIMED SABER and spectrometer temperatures. The Aura MLS results are for 8 August 2004 to 1 August 2006 and the TIMED SABER results for 26 January 2002 to 1 August 2006. $N$ is the number of points in each sample. Note that the Aura MLS $\mathrm{O}_{2}$ weighting is marginal with respect to the lowest recommended pressure $(0.001 \mathrm{hPa})$. See text for further details.

\begin{tabular}{|c|c|c|c|c|c|c|c|}
\hline \multicolumn{8}{|c|}{ Aura MLS and spectrometer temperatures 8 Aug 2004 to 1 Aug 2006} \\
\hline \multirow[t]{2}{*}{ Emission } & \multirow[t]{2}{*}{ Measurement } & \multirow[t]{2}{*}{ Mean $(\mathrm{K})$} & \multirow[t]{2}{*}{$N$} & \multicolumn{2}{|c|}{$\mathrm{AO}$} & \multicolumn{2}{|c|}{ SAO } \\
\hline & & & & Amplitude (K) & Phase (days) & Amplitude (K) & Phase (days) \\
\hline \multirow[t]{3}{*}{$\mathrm{OH}(\sim 87 \mathrm{~km})$} & $\begin{array}{l}\text { Spectrometer, } \\
\mathrm{OH}(6-2)\end{array}$ & $191.0 \pm 10.0$ & 7260 & $5.3 \pm 0.2$ & $168 \pm 2$ & $3.2 \pm 0.2$ & $83 \pm 1$ \\
\hline & $\begin{array}{l}\text { Aura MLS, } \\
\text { OH weighting }\end{array}$ & $183.5 \pm 8.2$ & 159 & $4.6 \pm 0.4$ & $164 \pm 5$ & $3.9 \pm 0.4$ & $97 \pm 3$ \\
\hline & Aura MLS, 0.46 Pa & $190.4 \pm 7.3$ & 159 & $5.1 \pm 0.4$ & $167 \pm 4$ & $3.7 \pm 0.4$ & $87 \pm 3$ \\
\hline \multirow[t]{2}{*}{$\mathrm{O}_{2}(\sim 94 \mathrm{~km})$} & $\begin{array}{l}\text { Spectrometer, } \\
\mathrm{O}_{2}(0-1)\end{array}$ & $205.3 \pm 34.0$ & 5477 & $4.7 \pm 0.7$ & $105 \pm 8$ & $3.7 \pm 0.7$ & $109 \pm 5$ \\
\hline & $\begin{array}{l}\text { Aura MLS, } \\
\mathrm{O}_{2}(0-1)\end{array}$ & $183.7 \pm 8.3$ & 159 & $4.1 \pm 0.9$ & $148 \pm 13$ & $4.5 \pm 0.8$ & $105 \pm 6$ \\
\hline \multicolumn{8}{|c|}{ TIMED SABER and spectrometer temperatures, 26 Jan 2002 to 1 Aug 2006} \\
\hline \multirow[t]{2}{*}{ Emission } & \multirow[t]{2}{*}{ Measurement } & \multirow[t]{2}{*}{ Mean $(\mathrm{K})$} & \multirow[t]{2}{*}{$N$} & \multicolumn{2}{|c|}{$\mathrm{AO}$} & \multicolumn{2}{|c|}{$\mathrm{SAO}$} \\
\hline & & & & Amplitude (K) & Phase (days) & Amplitude (K) & Phase (days) \\
\hline \multirow[t]{3}{*}{$\mathrm{OH}(\sim 87 \mathrm{~km})$} & $\begin{array}{l}\text { Spectrometer, } \\
\mathrm{OH}(6-2)\end{array}$ & $191.2 \pm 10.2$ & 27702 & $6.3 \pm 0.1$ & $182 \pm 1$ & $1.6 \pm 0.1$ & $84 \pm 1$ \\
\hline & $\begin{array}{l}\text { TIMED SABER, } \\
1.6 \mu \mathrm{m} \text { OH VER }\end{array}$ & $192.9 \pm 10.8$ & 1407 & $8.4 \pm 0.4$ & $177 \pm 3$ & $2.3 \pm 0.4$ & $95 \pm 5$ \\
\hline & $\begin{array}{l}\text { TIMED SABER, } \\
2.0 \mu \mathrm{m} \text { OH VER }\end{array}$ & $193.3 \pm 10.4$ & 1407 & $7.2 \pm 0.3$ & $175 \pm 3$ & $2.3 \pm 0.4$ & $98 \pm 5$ \\
\hline \multirow[t]{2}{*}{$\mathrm{O}_{2}(\sim 94 \mathrm{~km})$} & $\begin{array}{l}\text { Spectrometer, } \\
\mathrm{O}_{2}(0-1)\end{array}$ & $204.4 \pm 31.7$ & 21154 & $1.7 \pm 0.4$ & $150 \pm 11$ & $5.4 \pm 0.4$ & $102 \pm 2$ \\
\hline & $\begin{array}{l}\text { TIMED SABER, } \\
\mathrm{O}_{2}(0-1)\end{array}$ & $190.5 \pm 11.0$ & 1373 & $1.2 \pm 0.5$ & $118 \pm 20$ & $2.4 \pm 0.5$ & $98 \pm 5$ \\
\hline
\end{tabular}

\subsubsection{TIMED SABER v2.0 temperatures}

Table 2 also gives a summary of the same spectrometer temperatures compared to the coincident measurements from TIMED SABER. In contrast to the Aura MLS result, this comparison indicates that the mean spectrometer $\mathrm{OH}(6-2)$ temperatures are lower than the TIMED SABER temperatures, being 1.7 and $2.1 \mathrm{~K}$ lower than the $\mathrm{OH} 1.6 \mu \mathrm{m}$ and $\mathrm{OH}$ $2.0 \mu \mathrm{m}$ weighted temperatures, respectively. All mean $\mathrm{OH}$ temperatures agree to within the experimental uncertainty. The SABER 1.6 and $2.0 \mu \mathrm{m}$ AO amplitudes do not agree, but the corresponding phases and those of the SAO amplitudes and phases do agree. The TIMED SABER AO and SAO results do not agree with those from the spectrometer, but inspection of the results suggests that both instruments are measuring the same thing and that we have underestimated the spectrometer errors.

Like the Aura MLS temperatures, the $\mathrm{O}_{2}(0-1)$ spectrometer temperatures are greater than the TIMED SABER measurement when weighted to similar height ranges, in this case by $13.9 \mathrm{~K}$. The spectrometer $\mathrm{O}_{2}(0-1)$ mean temperatures are clearly biased high, although as we see below the $\mathrm{AO}$ and SAO amplitudes are very like those from the other instruments considered here. Given the larger number of coincident measurements with the spectrometer and the greater level of confidence in the TIMED SABER measurements at upper mesospheric heights, the TIMED SABER measurements have been used in preference to the Aura MLS measurements to recalibrate the spectrometer $\mathrm{O}_{2}(0-1)$ mean temperature throughout the remainder of this paper.

\section{Discussion}

\subsection{Temperatures}

As we have noted above, there have been many ground-based observational studies of midlatitude airglow temperatures in the Northern Hemisphere (e.g. She and Lowe, 1998; Bittner et al., 2002; López-González et al., 2007). Similar studies in the Southern Hemisphere are rarer (e.g. Buriti et al., 2004). 

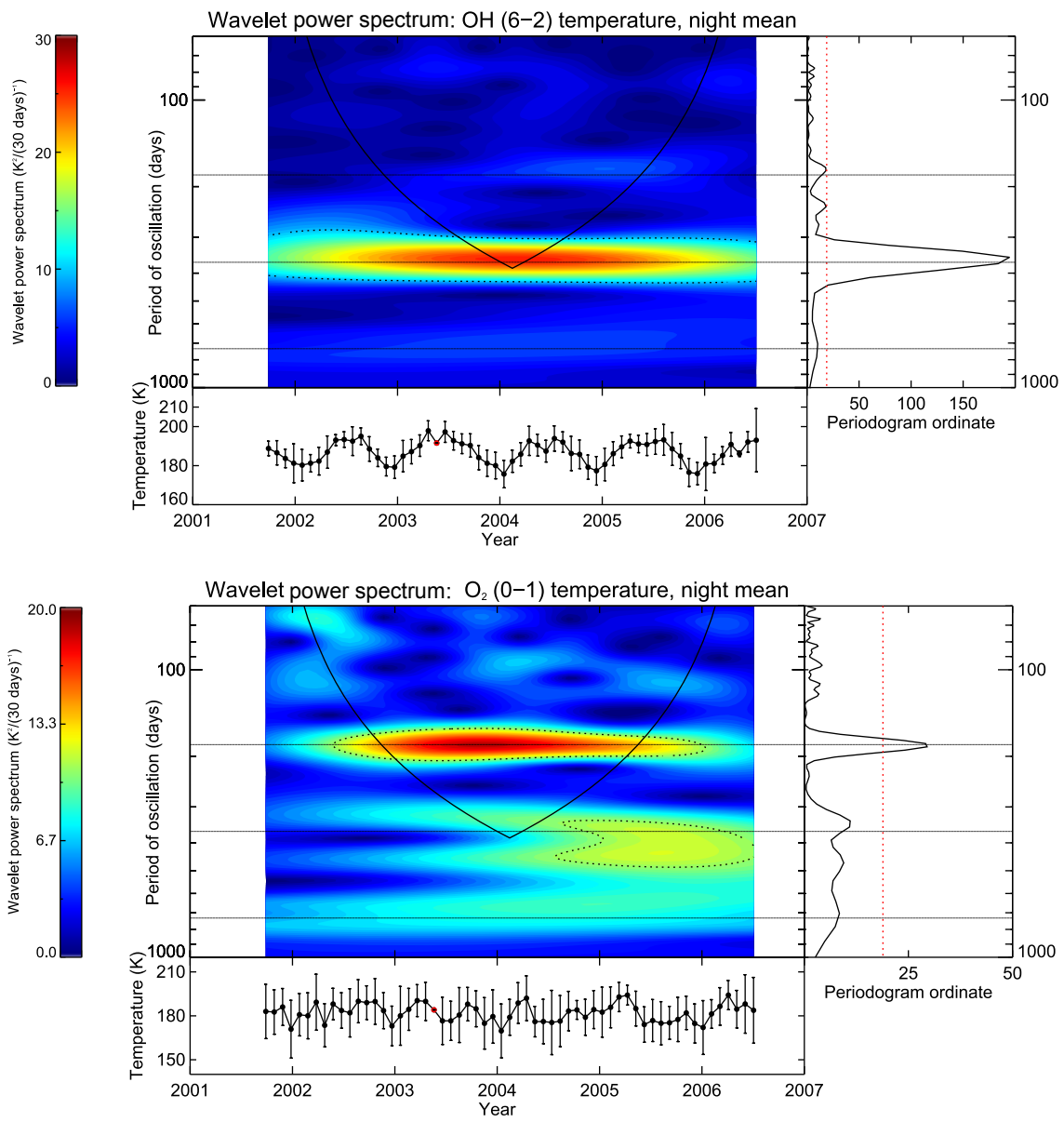

Figure 3. Top: the wavelet power spectrum for the $\mathrm{OH}(6-2)$ temperature (top) with the time series of 30-day averaged values and their standard deviations (bottom) and the corresponding Lomb periodogram (right). The periods of the SAO, AO, and QBO are indicated by the horizontal grey lines. The time series is dominated by the AO, which is consistent across the observational period in amplitude and phase. The SAO is present in the second half of the observational period and the QBO at its centre. Bottom: as for top panel, but for the $\mathrm{O}_{2}(0-1)$ temperatures. The SAO is the dominant periodicity in this times series, with more power in the AO later in the observational period. There is power in the wavelet spectrum at the period of the QBO, particularly after 2003, but not at a significant level when averaged over the entire observational period.

The most important of these for the present work is that of G08, which used coincident data from the Aerospace Buckland Park airglow imager. Table 3 summarises the $\mathrm{OH}(6-$ 2) temperature results from the present study, along with those from G08, who also include corresponding results from the TIME-GCM (Roble and Ridley, 1994). For this table, the periods of BP spectrometer observation times have been matched to those of G08. There is generally good agreement between these measurements, but not always to within the experimental uncertainties. However, we can summarise the results by saying that the mean temperature is in the range of 188 to $192 \mathrm{~K}$ with a mean of $190 \mathrm{~K}$, the AO is consistently about 3 times larger than the SAO and maximises in winter, and the SAO takes its first maximum in autumn.

Table 3 also summarises the $\mathrm{O}_{2}(0-1)$ temperature results and again compares these with G08 and the TIME-CGM. Again, we note that the mean from the present study is biased high, with a value $14.6 \mathrm{~K}$ greater than that of G08. However, the amplitudes of the AO and SAO agree to within their experimental uncertainties. The SAO is about twice the magnitude of the $\mathrm{AO}$ in the case of the experimental results, whereas the TIME-GCM has an AO a little larger than the SAO. The SAO phases are generally consistent, taking the first maxima in autumn, while the AO results for this study differ from the G08 and TIME-GCM results in taking their first maximum in autumn rather than in winter. We have already noted the noisy nature of our $\mathrm{O}_{2}(0-1)$ temperature results, and it may be that we have underestimated the uncertainties in our measurements in this case. Table 3 also includes MLT temperature results from the Wind Imaging Interferometer (WINDII) instrument on the Upper Atmosphere Research Satellite (UARS) (Shepherd et al., 2004), to which G08 also refer, and these are in general agreement with the ground-based observations. 
Table 3. $\mathrm{OH}$ and $\mathrm{O}_{2}$ results from the current study compared with other observations and the TIME-GCM. The time interval for the current results was selected to match that for G08. See text for details.

\begin{tabular}{|c|c|c|c|c|c|}
\hline \multicolumn{6}{|c|}{ Annual and semi-annual oscillation for $\mathrm{OH}$ emission temperatures } \\
\hline \multirow[t]{2}{*}{ OH temperature } & \multirow[t]{2}{*}{ Mean $(\mathrm{K})$} & \multicolumn{2}{|c|}{$\mathrm{AO}$} & \multicolumn{2}{|c|}{ SAO } \\
\hline & & Amplitude (K) & Phase (days) & Amplitude (K) & Phase (days) \\
\hline $\mathrm{OH}(6-2)$ & 192 & $6.7 \pm 0.5$ & $\begin{array}{r}183 \pm 4 \\
2 \mathrm{Jul} \text { (winter) }\end{array}$ & $2.0 \pm 1.4$ & $\begin{array}{r}89 \pm 10 \\
30 \text { Mar (autumn) }\end{array}$ \\
\hline $\mathrm{G} 08 \mathrm{OH}(6,2)$ & $189.2 \pm 0.3$ & $10.2 \pm 0.4$ & $213 \pm 2$ & $3.0 \pm 0.5$ & $113 \pm 4$ \\
\hline G08 TIME-GCM OH $(6,2)$ & $188.1 \pm 0.1$ & $9.1 \pm 0.2$ & $184 \pm 1$ & $2.6 \pm .2$ & $94 \pm 2$ \\
\hline WINDII, $87 \mathrm{~km}\left(35^{\circ} \mathrm{S}\right)$ (Shepherd et al., 2004) & $192.0 \pm 8.5$ & $5.8 \pm 0.3$ & $151.1 \pm 15.7$ & $1.8 \pm 1.2$ & $118.7 \pm 8.0$ \\
\hline Huang et al. (2006) (SABER, 2002 to 2004) & & & & 2.4 & 99 \\
\hline Xu et al. (2007) (SABER 2002 to 2006) & 195 & 12.5 & & 3.0 & Mid-year \\
\hline \multicolumn{6}{|c|}{ Annual and semi-annual oscillation for $\mathrm{O}_{2}$ emission temperatures } \\
\hline \multirow[t]{2}{*}{$\mathrm{O}_{2}$ temperature } & \multirow[t]{2}{*}{ Mean (K) } & \multicolumn{2}{|c|}{$\mathrm{AO}$} & \multicolumn{2}{|c|}{ SAO } \\
\hline & & Amplitude (K) & Phase (days) & Amplitude (K) & Phase (days) \\
\hline $\mathrm{O}_{2}(0-1)$ & 201 & $1.8 \pm 0.5$ & $\begin{array}{r}113 \pm 34 \\
23 \text { Apr (autumn) }\end{array}$ & $5.1 \pm 1.1$ & $\begin{array}{r}103 \pm 3 \\
13 \mathrm{Apr} \text { (autumn) }\end{array}$ \\
\hline $\mathrm{G} 08 \mathrm{O}_{2}(0,1)$ & $186.4 \pm 0.3$ & $2.6 \pm 0.5$ & $221 \pm 10$ & $4.7 \pm 0.4$ & $92 \pm 3$ \\
\hline G08 TIME-GCM O $2(0,1)$ & $188.9 \pm 0.2$ & $3.6 \pm 0.2$ & $206 \pm 4$ & $2.2 \pm .2$ & $84 \pm 3$ \\
\hline Huang et al. (2006) (SABER, 2002 to 2004) & & & & 2.5 & 108 \\
\hline
\end{tabular}
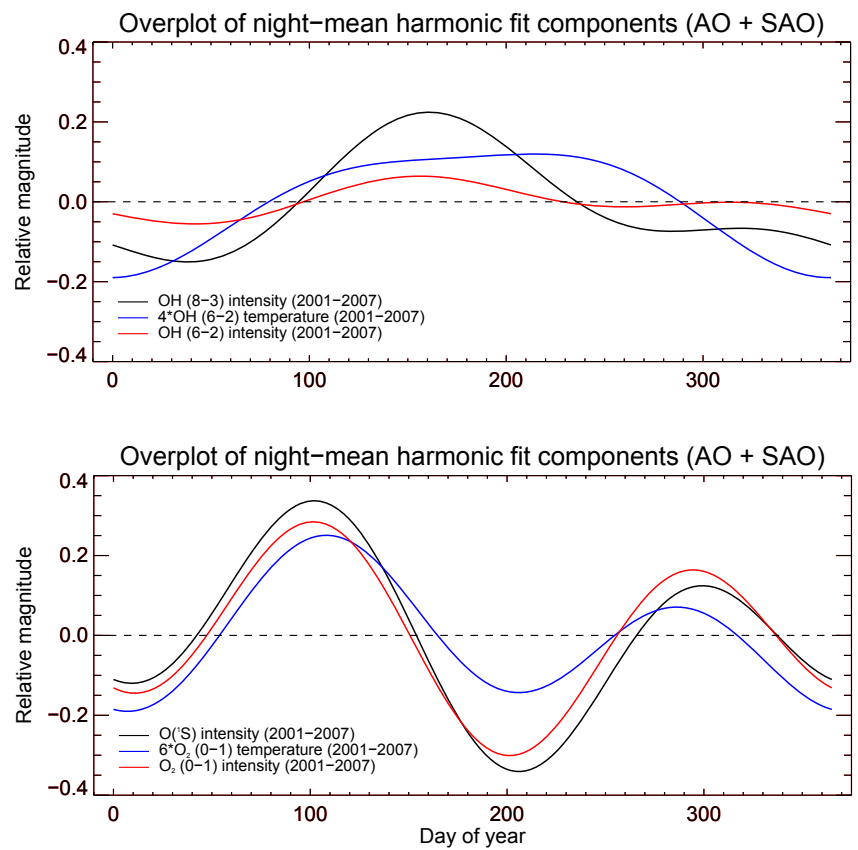

Figure 4. Top: a comparison of $\mathrm{AO}$ and $\mathrm{SAO}$ harmonic fits to the $\mathrm{OH}(6-2)$ rotational temperature and intensity from the spectrometer and the corresponding $\mathrm{OH}(8-3)$ intensity from the 3FP for the period 2001 to 2007. Bottom: as for top panel, but for the $\mathrm{O}_{2}(0-1)$ rotational temperature and intensity and the corresponding $\mathrm{O}\left({ }^{1} \mathrm{~S}\right)$ intensity from the 3FP.
Table 3 also summarises TIMED SABER results from $\mathrm{Xu}$ et al. (2007) and Huang et al. (2006). Xu et al. (2007) used TIMED SABER observations to examine long-term variations in zonal mean temperatures in the years 2002 to 2006. Their results indicate that the mean was $195 \mathrm{~K}$ for $86 \mathrm{~km}$ at $40^{\circ} \mathrm{S}$ and that the AO maximises mid-year with a value of $12.5 \mathrm{~K}$. They found the SAO was weaker in amplitude with a value of $3 \mathrm{~K}$, both results being consistent with ours. They also found a QBO with an amplitude of $0.4 \mathrm{~K}$. We do not find a significant QBO in our $\mathrm{OH}(6-2)$ nightly mean temperatures, which would correspond to the height of $\mathrm{Xu}$ et al.'s (2007) observations near $86 \mathrm{~km}$. It is significant in the 00:00 to 03:00 LT data block, however. Huang et al. (2006) also looked at SABER observed temperatures but concentrated on the QBO and SAO. They found the SAO at $35^{\circ} \mathrm{S}$ to be $2.4 \mathrm{~K}$ with a phase of 99 days at $87 \mathrm{~km}$ and $2.5 \mathrm{~K}$ with a phase of 108 days at $94 \mathrm{~km}$, in agreement with the results of the present study and with the others summarised in Table 3. More recently, Zhang et al. (2017) analysed TIMED SABER results from January 2002 to February 2015 and provided results for the SAO at $85 \mathrm{~km}$ in good general agreement with our spectrometer $\mathrm{OH}(6-2)$ results.

\subsection{Temperature and intensity intercomparison}

In the case of the $\mathrm{OH}$ emission shown in Fig. 4, a strong correlation between the temperature and intensity is typical of other studies. For example, Shepherd et al. (2007) looked at winter results from Resolute Bay $\left(74.7^{\circ} \mathrm{N}\right)$ and Espy et al. (2007) looked at two sites in Sweden (59.5 and 57.4 ${ }^{\circ} \mathrm{N}$ ). Both studies showed a strong correlation throughout the year, 

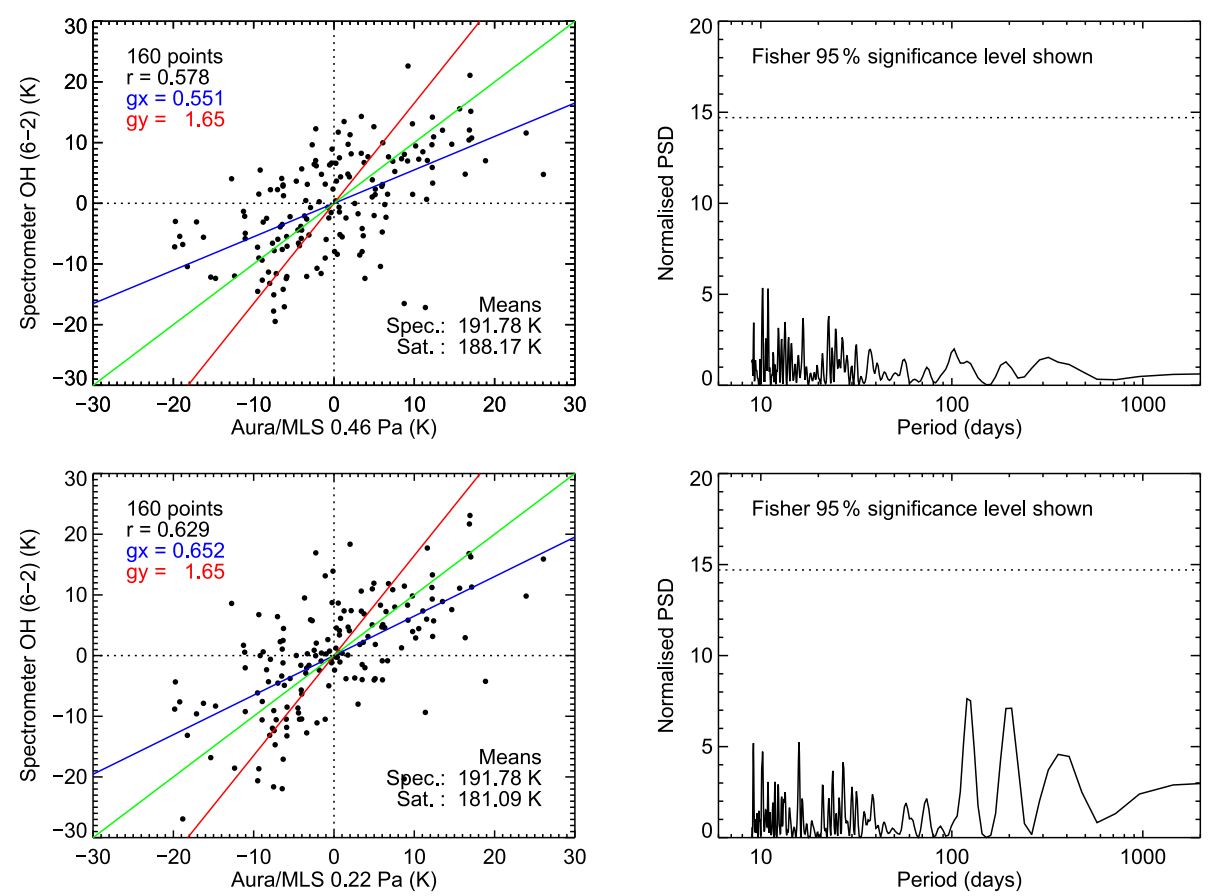

Figure 5. Examples of the comparison between the spectrometer $\mathrm{OH}$ temperatures and the Aura MLS temperatures. The panels on the left show the correlation values between the spectrometer and Aura MLS temperatures for the $0.46 \mathrm{~Pa}$ (top) and the $0.22 \mathrm{~Pa}$ (bottom) retrieval levels. The blue and red lines indicate lines of best fit made assuming all experimental errors are in the Aura MLS and the spectrometer, respectively. The green line indicates the $y=x$ line. The right-hand panels indicate Lomb-Scargle periodograms for the residuals between the spectrometer and Aura MLS temperatures corresponding to the left-hand panels.

with the latter study also finding a seasonal dependence in the level of correlation. Espy et al. (2007) suggested that this was due to a variation in the mixing ratio of atomic oxygen due to vertical motion. Smith (2012) considered temperature and intensity observations of $\mathrm{OH}(6-2)$ made at Millstone Hill $\left(42.6^{\circ} \mathrm{N}, 71.5^{\circ} \mathrm{W}\right)$, a site with a co-latitude somewhat closer to ours. He found a strong correlation, with a marked seasonal dependence and concluded that dynamical effects dominated photochemical effects. The correlation between the two parameters was highest during the autumn and lowest during the summer by a factor of over 3.6. He suggested that the summer minimum resulted from an increase in mesospheric gravity wave activity during the summer, a feature not predicted by the Mass-Spectrometer-IncoherentScatter (MSIS) model (Hedin, 1991) data but clearly observed by Ern et al. (2011) in High Resolution Dynamics Limb Sounder (HIRDLS) and SABER measurements of gravity wave momentum flux in the stratosphere and mesosphere. The $\mathrm{OH}(6-2)$ results from the present study are consistent with Smith's (2012) results. We also note that the $\mathrm{OH}(8-3)$ results show a very similar form to the $\mathrm{OH}(6-2)$ results.

In the case of the $\mathrm{O}_{2}(0-1)$ emission, we see a strong correlation between the temperature and the intensity and with the OI $558 \mathrm{~nm}$ emission intensity. Reid et al. (2014) have also noted that at Adelaide there is a striking correspondence be- tween the $\mathrm{O}_{2}(0-1)$ temperature maximum, the time of greatest $\mathrm{O}\left({ }^{1} \mathrm{~S}\right)$ brightness (Reid and Woithe, 2007), and the time of the maximum meridional wind, which would correspond to the downward phase of the diurnal tide at equinox later in the night. This is consistent with the transport of atomic oxygen down into the MLT region and the brightening of the $\mathrm{O}\left({ }^{1} \mathrm{~S}\right)$ and $\mathrm{OH}(8-3)$ airglow late in the night as observed at the autumnal equinox.

\subsection{Determination of the $\mathrm{OH}$ emission height}

Thus far we have assumed that the $\mathrm{OH}$ emission occurred at a fixed and known geometrical height. In the next two sections, we consider whether we can improve on this assumption, firstly by looking for the height of the minimum residual between the spectrometer and the satellite temperatures for different satellite pressure heights and then by interpolating the SABER temperatures to a fixed density surface derived from meteor radar observations.

\subsubsection{Comparison of spectrometer OH and Aura MLS temperatures at different Aura MLS constant pressure levels}

The simplest Gaussian averaging kernel we have applied to the satellite data assumes that the $\mathrm{OH}$ layer is at a fixed altitude. However, when we use the assumption of a fixed 
height for the $\mathrm{OH}$ emission and plot the residual temperature (ground-based - satellite), we find that the residuals for the Gaussian-weighted satellite data show a seasonal behaviour, suggesting that the mean emission height is changing throughout the year. When we examine the LombScargle periodograms of the residuals for temperatures at a series of constant pressure surfaces derived from the Aura MLS observations using the same conditions for coincidence as described earlier, we find that the residual minimises for MLS temperature estimates at the native retrieval level of $0.46 \mathrm{~Pa}(\sim 83.3 \mathrm{~km})$, with a correlation value of $r=0.58$. This is shown in Fig. 5. This figure also shows the results for the $0.22 \mathrm{~Pa}(\sim 87.6 \mathrm{~km})$ retrieval level. The long period components (TAO, SAO, $\mathrm{AO})$ of the residual are larger at this level, but the correlation is better at $r=0.63$. All the peaks in both residuals are below the $99 \%$ significance level, but given the width of the emission layer, this approach is not likely to be a good predictor of the retrieval level of best agreement. We should note here that in the height range of $70-90 \mathrm{~km}$ there are only four or five retrieval levels, and in the present study, it is not clear that we can distinguish between results at the 0.22 and $0.46 \mathrm{~Pa}$ retrieval levels.

We have included the $0.46 \mathrm{~Pa}$ result in Table 2 for the period between 8 August 2004 and 1 August 2006 as an example. The 0.46 Pa Aura MLS and spectrometer $\mathrm{OH}(6-2)$ results agree quite closely, with the mean of the former being $1.4 \mathrm{~K}$ lower than the latter. This difference is consistent with the bias reported for MLS (see Livesey et al., 2011). We note that there is arguably better agreement between the $\mathrm{OH}$ spectrometer result and the Aura MLS temperature at the $0.46 \mathrm{~Pa}$ retrieval level, with the $\mathrm{AO}$ and SAO amplitudes and phases at the $0.46 \mathrm{~Pa}$ retrieval level in closer agreement with the spectrometer results than those from the fixed weighting function.

Irrespective of the actual level of best agreement, the behaviour of these residuals suggests that the $\mathrm{OH}$ temperatures measured by the spectrometer are more closely associated with the layer being tied to a constant pressure surface rather than a fixed geometric height. This would be consistent with the density of atomic oxygen being tied to the background density (see, e.g., Marsh et al., 2006) and with the model results for the hydroxyl layer of Grygalashvyly et al. (2014).

\subsubsection{Comparison of spectrometer $\mathrm{OH}$ temperatures with SABER temperatures at meteor-radar-derived density levels}

Additional information about the $\mathrm{OH}$ emission heights may be obtained by calibrating meteor radar results using Aura MLS (or SABER) densities, as Younger et al. (2015) have shown. They showed that a constant density surface may be determined in the 78 to $85 \mathrm{~km}$ height region from vertical profiles of meteor trail radar echo decay times. Additional work by P. J. Younger (personal communication, 2016) indicates that a second upper constant density surface between

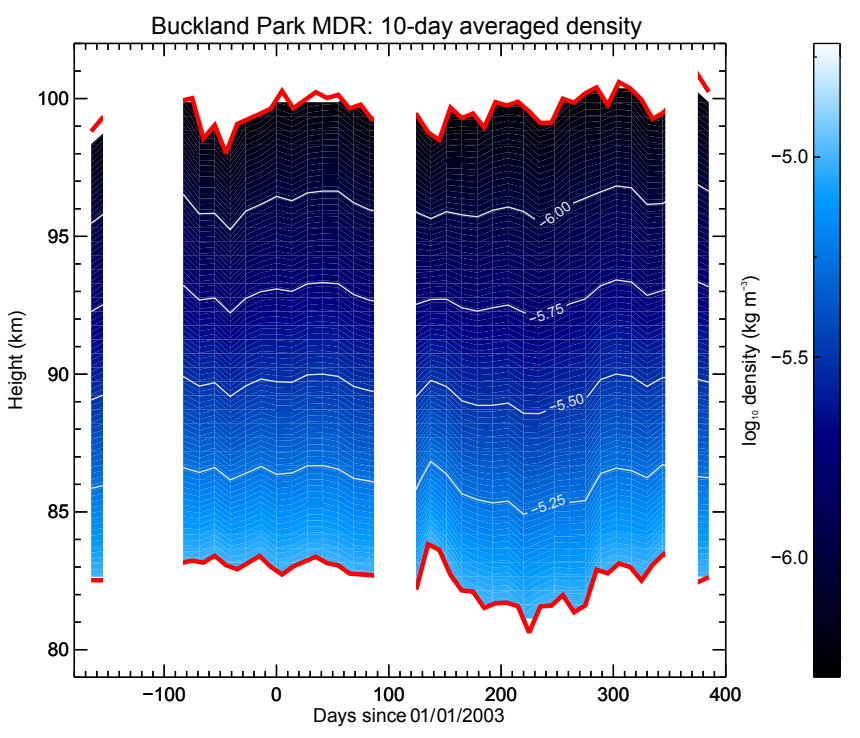

Figure 6. The geometric heights for 10-day average fixed density surfaces for 14 May 2002 to 28 January 2004 determined from the meteor radar. This diagram has been prepared using the difference in the estimate of the geometric height of two constant density surfaces to calculate the density scale height, $H^{*}$. The density profile is then interpolated between the two surfaces. Once the density or temperature dependence of the airglow layer is known, the density profile can be used to infer the height to which airglow temperatures correspond.

95 and $100 \mathrm{~km}$ may be determined. With some assumptions, this allows the constant density surfaces to be determined independently of satellite measurements after "calibration" for a particular meteor radar wavelength. While we do not have meteor radar observations for the entire period of the spectrometer observations, we do have coincident $33.2 \mathrm{MHz}$ meteor radar, $T_{\mathrm{OH}}, T_{\mathrm{O}_{2}}$, and SABER observations between 14 May 2002 and 28 January 2004. We now consider this period for further intercomparison as an example of this approach.

First, we weight the SABER temperatures with a Gaussian emulating the OH VER (which is centred on interpolated heights of "fixed" density and has a full width at half minimum (FWHM) of $8 \mathrm{~km}$ ). Then we use two methods to evaluate the density scale height, $H^{*}$, from which a grid of fixed density surfaces is created. In the first approach, we evaluate $H^{*}$ (assuming $H^{*}=H$, the pressure scale height) using an interpolated SABER temperature at the height in question, and in the second, we estimate $H^{*}$ directly from the slope of the two densities at the two heights predicted by the meteor technique. These were found to be effectively equivalent.

The meteor data used in this work were acquired before the development of the phase calibration technique described by Holdsworth et al. (2004b) which uses the meteor echoes themselves to calibrate the radar. A post-statistics approach was used to improve the phase characteristics of the meteor 

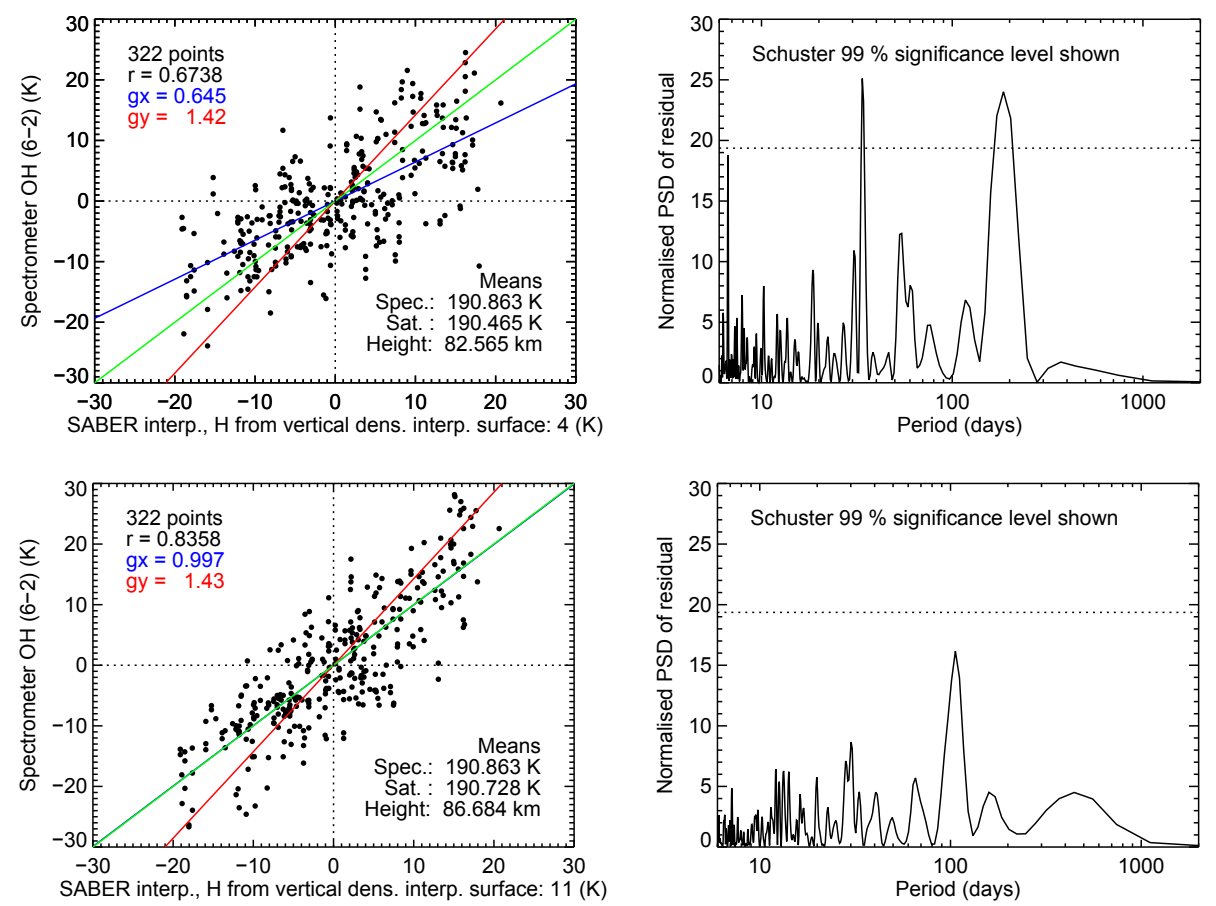

Figure 7. Two examples of the comparison between the spectrometer $\mathrm{OH}$ temperatures and the SABER temperatures interpolated to constant density surfaces. The panels on the left show the correlation values between the spectrometer and SABER temperatures for two density surfaces. The blue and red lines indicate lines of best fit made assuming that all experimental errors are in the SABER and spectrometer, respectively. The green line indicates the $y=x$ line. The right-hand panels indicate Lomb-Scargle periodograms for the residuals between the spectrometer and SABER temperatures corresponding to the left-hand panels.

Table 4. Comparison between coincident TIMED SABER and spectrometer temperatures for the period 16 July 2002 to 25 January 2004 when the meteor radar data were available to calculate the neutral density. $\mathrm{N}$ is the number of points in each sample. See text for further details.

TIMED SABER and spectrometer temperatures, 16 Jul 2002 to 25 Jan 2004

\begin{tabular}{|c|c|c|c|c|c|c|c|}
\hline \multirow[t]{2}{*}{ Emission } & \multirow[t]{2}{*}{ Measurement } & \multirow[t]{2}{*}{ Mean $(\mathrm{K})$} & \multirow[t]{2}{*}{$N$} & \multicolumn{2}{|c|}{$\mathrm{AO}$} & \multicolumn{2}{|c|}{$\mathrm{SAO}$} \\
\hline & & & & Amplitude (K) & Phase (days) & Amplitude (K) & Phase (days) \\
\hline \multirow[t]{4}{*}{$\mathrm{OH}(\sim 87 \mathrm{~km})$} & Spectrometer, $\mathrm{OH}(6-2)$ & $190.4 \pm 9.9$ & 5,699 & $7.7 \pm 0.2$ & $186 \pm 1$ & $3.3 \pm 0.2$ & $76 \pm 1$ \\
\hline & SABER, MDR density & $190.7 \pm 10.9$ & 322 & $9.0 \pm 0.8$ & $186 \pm 5$ & $3.5 \pm 0.9$ & $72 \pm 5$ \\
\hline & SABER, $1.6 \mu \mathrm{m}$ OH VER & $191.3 \pm 10.6$ & 279 & $8.5 \pm 0.8$ & $186 \pm 5$ & $2.9 \pm 0.9$ & $81 \pm 7$ \\
\hline & SABER, $2.0 \mu \mathrm{m}$ OH VER & $192.4 \pm 10.4$ & 279 & $7.8 \pm 0.8$ & $182 \pm 6$ & $3.2 \pm 0.9$ & $86 \pm 7$ \\
\hline
\end{tabular}

returns, but because the radar was being used in a variety of different experimental modes during this period, it likely that the data are not of the quality of more recent meteor radar observations, and 10-day averages were used to determine the fixed density contours. These are shown in Fig. 6. Inspection of this figure indicates that variations in geometrical height of the constant density surfaces are generally less than $2 \mathrm{~km}$ on this timescale.

Figure 7 shows two examples of the comparison between the spectrometer and SABER temperatures on constant density surfaces. The density surface in the upper panels corresponds exactly to the lower curve height estimates, and the one in the lower panels corresponds to a surface interpo- lated between the lower and upper curves. Using the $\log _{10} \rho$ values for the lower- and upper-curve heights predicted by P. J. Younger (personal communication, 2016) for Troms $\emptyset$ (which are $-4.99 \pm 0.07$ and $-6.19 \pm 0.18 \mathrm{~kg} \mathrm{~m}^{-3}$, respectively), we estimate that the $\log _{10} \rho$ value for the surface in the lower panels of Fig. 6 is $-5.29 \pm 0.25 \mathrm{~kg} \mathrm{~m}^{-3}$. The summary of the correlation and temperature differences for the entire height range is shown in Fig. 8. The maximum correlation obtained in the 79 to $95 \mathrm{~km}$ height range is about 0.84 , at a mean height of just under $87 \mathrm{~km}(86.7 \mathrm{~km})$. The lowest mean discrepancy between the two data sets is also at the same height, which is negligible $(0.14 \mathrm{~K})$. This represents our best level of mean agreement and correlation obtained 


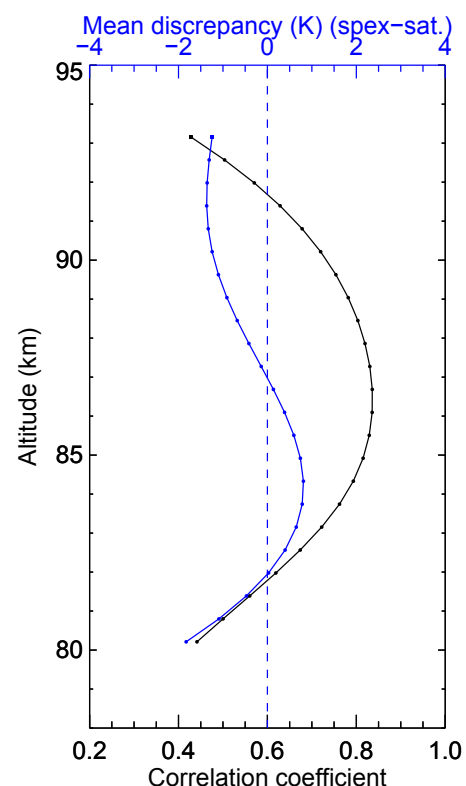

Figure 8. The correlation coefficient and the mean discrepancy between the spectrometer $\mathrm{OH}$ temperatures and the SABER temperatures when the latter are interpolated to a series of constant density levels. See text for further details.

between the spectrometer and SABER (and Aura, for that matter) temperatures (including weighting with OH VER and using measurements on fixed pressure surfaces). This means that the airglow layer appears to track the constant density surfaces estimated by the meteor technique more closely than the VER and pressure surface estimates provided by SABER.

To extend the intercomparison beyond a simple correlation, we harmonically analysed the $\mathrm{OH}$ data as we have done above. The results are shown in Table 4. This table shows a comparison between the spectrometer $\mathrm{OH}$ results for the period of the meteor radar observations, along with the coincident SABER results, both for the meteor radar determined constant density surfaces ("SABER MDR") and for the 1.6 and $2.0 \mu \mathrm{m} \mathrm{OH}$ VERs. Inspection of this table suggests good general agreement overall between the different weightings, with better agreement between the spectrometer $\mathrm{OH}$ and SABER MDR results for the mean temperature and the phase of the SAO but not for the other parameters, where either the 1.6 and $2.0 \mu \mathrm{m}$ OH VER weightings do better. So, while the overall correlations are improved by using a density surface weighting, the individual results from the harmonic fits are not necessary improved. Clearly, further intercomparisons using more recent meteor radar results is suggested.

It is pleasing that the mean geometric height for the $\mathrm{OH}$ emission determined here $(\sim 86.7 \mathrm{~km})$ is consistent with the empirically determined value of Baker and Stair (1988), and so the conclusions we reached earlier on the long-term variation of the airglow intensity and temperature variations remain valid. We also note that a 16-night comparison by Zhao et al. (2005) between the University of Illinois $\mathrm{Na}$ wind and temperature lidar and the Utah State University CEDAR Mesospheric Temperature Mapper at the summit of Haleakalā Crater in Hawaii $\left(20.8^{\circ} \mathrm{N}, 156.2^{\circ} \mathrm{W}\right)$ found a mean nocturnal altitude of $88.6 \mathrm{~km}$ with a nocturnal variability of $\pm 3.0 \mathrm{~km}$ for the $\mathrm{OH}(6,2)$ band emission layer. Trials with more recent meteor radar observations indicate that quality density estimates are possible with a $4 \mathrm{~h}$ sampling (P. J. Younger, personal communication, 2016). This strongly suggests that a meteor radar could be used to better determine the airglow emission height over relatively short timescales.

\section{Summary and conclusions}

$\mathrm{OH}(6-2)$ and $\mathrm{O}_{2}(0-1)$ airglow emission observations show significant annual and semi-annual oscillations in both temperature and intensity. In the $\mathrm{OH}(6-2)$, the SAO maximises in the autumn and the $\mathrm{AO}$ in the winter. The $\mathrm{AO}$ takes a peak value of $6.6 \pm 0.6 \mathrm{~K}$ and the $\mathrm{SAO}$ a peak value of $2.1 \pm 1.3 \mathrm{~K}$. In the case of the $\mathrm{O}_{2}(0-1)$ temperatures, both the $\mathrm{SAO}$ and $\mathrm{AO}$ maximise in the autumn, with the SAO dominant at $5.1 \pm 1.3 \mathrm{~K}$, about twice the magnitude of the $\mathrm{AO}$ at $2.6 \pm 0.9 \mathrm{~K}$. The intensities show a similar variation through the year, with that between the $\mathrm{O}_{2}(0-1)$ temperatures and intensities being striking. The $\mathrm{O}\left({ }^{1} \mathrm{~S}\right)$ intensity shows a similarly strong agreement with the $\mathrm{O}_{2}(0-1)$ temperature and intensity.

$\mathrm{OH}(6-2)$ temperatures measured in the present work agree well with coincident measurements, with TIME-GCM results, and with WINDII observations reported previously by Gelinas et al. (2008). Our $\mathrm{O}_{2}(0-1)$ temperatures overestimate their mean but otherwise generally agree well with their results. Our results also agree with SABER and Aura MLS results presented previously for our location.

We used Aura MLS and TIMED SABER results to compare with our spectrometer results. We find good agreement between our $\mathrm{OH}(6-2)$ temperature measurements and $\mathrm{OH}$ weighted Aura MLS results for the mean, AO, and SAO, all agreeing to within the experimental uncertainty, with the suggestion of a downward bias in the Aura MLS mean temperature. We find better agreement between the techniques when we use the Aura MLS results from the 0.46 and $0.22 \mathrm{~Pa}$ retrieval levels where the residuals between the techniques minimise and the correlation coefficients maximise.

Our spectrometer $\mathrm{O}_{2}(0-1)$ mean temperature results are biased high but agree with those from $\mathrm{O}_{2}(0-1)$ weighted Aura MLS results to within the experimental uncertainty. The amplitude of the $\mathrm{AO}$ and the amplitude and phase of the SAO agree for the two techniques, but the phases of the AO do not. We note that we are at the limit of the validity for the Aura MLS measurements and that our $\mathrm{O}_{2}(0-1)$ observations are quite noisy.

In the case of the SABER results, we find SABER 1.6 and $2.0 \mu \mathrm{m}$ VER weighted temperatures and the spectrometer $\mathrm{OH}(6-2)$ mean temperatures agree well over the 4.5 years of coincident measurements, but not to within the experimental 
uncertainties. The spectrometer $\mathrm{O}_{2}(0-1)$ temperatures agree to within the experimental uncertainties with the SABER temperatures using an $\mathrm{O}_{2}(0-1)$ weighting, but the spectrometer uncertainties are large and the mean temperature is clearly an overestimate.

We used the SABER temperature results to show that the $\mathrm{OH}$ airglow emission heights appear to follow meteor-radarderived constant density surfaces, and even at the relatively coarse sampling resolution of 10 days, using this to calculate the emission height significantly improves the correlation between the spectrometer $\mathrm{OH}$ and the SABER temperatures. Based on more recent meteor observations, this suggests that its application to more recent meteor radars would offer a way of better determining the actual emission height over time periods of $6 \mathrm{~h}$ or less.

Data availability. Aura MLS data are available from http://disc.sci. gsfc.nasa.gov/Aura/data-holdings/MLS. TIMED SABER data are available from http://saber.gats-inc.com/data.php. Buckland Park radar and optical data are available from the University of Adelaide upon request.

Competing interests. ATRAD Pty Ltd partially funded this work through the involvement of Iain M. Reid, Jonathan M. Woithe, and Joel P. Younger. An ATRAD meteor detection radar was used for the meteor observations used here.

Acknowledgements. Funding for this research was provided by the Australian Research Council grants A69943065, DP0450787, DP0878144, and DP1096901, by the Adelaide University ARC Small Grants Scheme, and by ATRAD Pty Ltd. The IDL wavelet analysis software was provided by C. Torrence and G. Compo, and is available at http://atoc.colorado.edu/research/wavelets/.

The topical editor, A. J. Kavanagh, thanks A. Liu and one anonymous referee for help in evaluating this paper.

\section{References}

Baker, D. J. and Stair, A. T.: Rocket measurements of the altitude distributions of the hydroxyl airglow, Phys. Scripta, 37, 611, doi:10.1088/0031-8949/37/4/021, 1988.

Bittner, M., Offermann, D., Graef, H.-H., Donner, M., and Hamilton. K.: An 18-year time series of $\mathrm{OH}$ rotational temperatures and middle atmosphere decadal variations, J. Atmos. Sol.-Terr. Phy., 64, 1147-1166, doi:10.1016/S1364-6826(02)00065-2, 2002.

Buriti, R. A., Takahashi, H., Gobbi, D., de Medeiros, A. F., Nepomuceno, A. A., and Lima, L. M.: Semiannual oscillation of the mesospheric airglow at $7.4^{\circ} \mathrm{S}$ during the PSMOS observation period of 1998-2001, J. Atmos. Sol.-Terr. Phy., 66, 567-572, doi:10.1016/j.jastp.2004.01.009, 2004.

Coxon, J. A. and Foster, S. C.: Rotational analysis of hydroxyl vibration-rotation emission bands: Molecular constants for $\mathrm{OH}$
$\mathrm{X} 2 \Pi, 6 \leq v \leq 10$, Can. J. Phys., 60, 41-48, doi:10.1139/p82006, 1982.

Ding, F., Yuan, H., Wan, W., Reid, I. M., and Woithe, J. M.: Occurrence characteristics of medium-scale gravity waves observed in $\mathrm{OH}$ and OI nightglow over Adelaide $\left(34.5^{\circ} \mathrm{S}, 138.5^{\circ} \mathrm{E}\right)$, J. Geophys. Res., 109, D14104, doi:10.1029/2003JD004096, 2004.

Ern, M., Preusse, P., Gille, J. C., Hepplewhite, C. L., Mlynczak, M. G., Russell III, J. M., and Riese, M.: Implications for atmospheric dynamics derived from global observations of gravity wave momentum flux in stratosphere and mesosphere, J. Geophys. Res., 116, D19107, doi:10.1029/2011JD015821, 2011.

Espy, P. J., Stegman, J., Forkman, P., and Murtagh, D.: Seasonal variation in the correlation of airglow temperature and emission rate, Geophys. Res. Lett., 34, L17802, doi:10.1029/2007GL031034, 2007.

French, W. J. R. and Mulligan, F. J.: Stability of temperatures from TIMED/SABER v1.07 (2002-2009) and Aura/MLS v2.2 (2004-2009) compared with $\mathrm{OH}(6-2)$ temperatures observed at Davis Station, Antarctica, Atmos. Chem. Phys., 10, 1143911446, doi:10.5194/acp-10-11439-2010, 2010.

Gelinas, L. J., Hecht, J. H., Walterscheid, R. L., Roble, R. G., and Woithe, J. M.: A seasonal study of mesospheric temperatures and emission intensities at Adelaide and Alice Springs, J. Geophys. Res., 113, A01304, doi:10.1029/2007JA012587, 2008.

Greet, P. A., French, W. J. R., Burns, G. B., Williams, P. F. B., Lowe, R. P., and Finlayson, K.: OH(6-2) spectra and rotational temperature measurements at Davis, Antarctica, Ann. Geophys., 16, 7789, doi:10.1007/s00585-997-0077-3, 1998.

Grygalashvyly, M., Sonnemann, G. R., Lübken, F.-J., Hartogh, P., and Berger U.: Hydroxyl layer: Mean state and trends at midlatitudes, J. Geophys. Res.-Atmos., 119, 12391-12419, doi:10.1002/2014JD022094, 2014.

Hecht, J. H., Walterscheid, R. L., and Ross, M. N.: First measurements of the two-dimensional horizontal wave number spectrum from CCD images of the nightglow, J. Geophys. Res., 99, 1144911460, doi:10.1029/94JA00584, 1994.

Hecht, J. H., Walterscheid, R. L., Woithe, J., Campbell, L., Vincent, R. A., and Reid, I. M.: Trends in airglow imager observations near Adelaide, Australia, Geophys. Res. Lett., 24, 587-590, 1997.

Hedin, A. E.: Extension of the MSIS thermospheric model into the middle and lower atmosphere, J. Geophys. Res., 96, 1159-1172, doi:10.1029/90JA02125, 1991.

Hobbs, B. G., Reid I. M., and Greet, P. A.: Mesospheric rotational temperatures obtained from the $\mathrm{OH}(6-2)$ transition at Adelaide, Australia, J. Atmos. Terr. Phys., 58, 1337-1344, doi:10.1016/0021-9169(95)00168-9, 1996.

Holdsworth, D. A., Reid, I. M., and Cervera, M. A.: Buckland Park all-sky interferometric meteor radar, Radio Sci., 39, RS5009, doi:10.1029/2003RS003014, 2004a.

Holdsworth, D. A., Tsutsumi, M., Reid, I. M., Nakamura, T., and Tsuda, T.: Interferometric meteor radar phase calibration using meteor echoes, Radio Sci., 39, RS5012, doi:10.1029/2003RS003026, 2004b.

Holdsworth, D. A., Morris, R. J., Murphy, D. J., Reid, I. M., Burns, G. B., and French, W. J. R.: Antarctic mesospheric temperature estimation using the Davis mesospherestratosphere-troposphere radar, J. Geophys. Res., 111, D05108, doi:10.1029/2005JD006589, 2006. 
Huang, F. T., Mayr, H. G., Reber, C. A., Russell, J. M., M Mlynczak, and Mengel, J. G.: Stratospheric and mesospheric temperature variations for the quasi-biennial and semiannual (QBO and SAO) oscillations based on measurements from SABER (TIMED) and MLS (UARS), Ann. Geophys., 24, 2131-2149, doi:10.5194/angeo-24-2131-2006, 2006.

Jones Jr., M., Emmert, J. T., Drob, D. P., and Siskind, D. E.: Middle atmosphere dynamical sources of the semiannual oscillation in the thermosphere and ionosphere, Geophys. Res. Lett., 44, 1221, doi:10.1002/2016GL071741, 2017.

Krassovsky, V. I., Shefov, N. N., and Yarin, V. I.: Atlas of the airglow spectrum 3000-12400 ̊, Planet. Space Sci., 9, 883-915, doi:10.1016/0032-0633(62)90008-9, 1962.

Langhoff, S. R., Werner, H. J., and Rosmus, P.: Theoretical transition probabilities for the OH Meinel system, J. Mol. Spectrosc., 118, 507-529, doi:10.1016/0022-2852(86)90186-4, 1986.

Lee, C., Kim, J.-H., Jee, G., Lee, W., Song, I.-S., and Kim, Y. H.: New method of estimating temperatures near the mesopause region using meteor radar observations, Geophys. Res. Lett., 43, 10580-10585, doi:10.1002/2016GL071082, 2016.

Lee, C. S., Younger, J. P., Reid, I. M., Kim, Y. H., and Kim, J.-H.: The effect of recombination and attachment on meteor radar diffusion coefficient profiles, J. Geophys. Res.-Atmos., 118, 30373043, doi:10.1002/jgrd.50315, 2013.

Livesey, N. J., Read, W. G., Froidevaux, L., Lambert, A., Manney, G. L., Pumphrey, H. C., Santee, M. L., Schwartz, M. J., Wang, S., Cofeld, R. E., Cuddy, D. T., Fuller, R. A., Jarnot, R. F., Jiang, J. H., Knosp, B. W., Stek, P. C., Wagner, P. A., and Wu, D. L.: EOS MLS Version 3.3 Level 2 data quality and description document, version 3.3x-1.0, JPL D-33509, Jet Propul. Lab., Pasadena, California, 2011.

López-González, M.J., García-Comas, M., Rodríguez, E., LópezPuertas, M., Shepherd, M. G., Shepherd, G. G., Sargoytchev, S., Aushev, V. M., Smith, S. M., Mlynczak, M. G., Russell, J. M., Brown, S., Cho, Y.-M., and Wiens, R. H.: Ground-based mesospheric temperatures at mid-latitude derived from $\mathrm{O}_{2}$ and $\mathrm{OH}$ airglow SATI data: Comparison with SABER measurements, J. Atmos. Sol.-Terr. Phy., 69, 23792390, doi:10.1016/j.jastp.2007.07.004, 2007.

Marsh, D. R., Smith, A. K., Mlynczak, M. G., and Russell III, J. M.: SABER observations of the $\mathrm{OH}$ Meinel airglow variability near the mesopause, J. Geophys. Res., 111, A10S05, doi:10.1029/2005JA011451, 2006.

McDade, I. C.: The photochemistry of the MLT oxygen airglow emissions and the expected influences of tidal perturbations, Adv. Space Res., 21, 787-794, doi:10.1016/S02731177(97)00674-1, 1998.

Mies, F.: Calculated vibrational transition probabilities of $\mathrm{OH}\left(\mathrm{X}^{2} \Pi\right)$, J. Mol. Spectrosc., 53, 150-188, doi:10.1016/00222852(74)90125-8, 1974.

Noll, S., Kausch, W., Kimeswenger, S., Unterguggenberger, S., and Jones, A. M.: Comparison of VLT/X-shooter $\mathrm{OH}$ and $\mathrm{O}_{2}$ rotational temperatures with consideration of TIMED/SABER emission and temperature profiles, Atmos. Chem. Phys., 16, 50215042, doi:10.5194/acp-16-5021-2016, 2016.

Reid, I. M. and Woithe, J. M.: Three Field Photometer Observations of short period gravity wave intrinsic parameters in the 80 to $100 \mathrm{~km}$ height region, J. Geophys. Res., 110, D21108, doi:10.1029/2004JD005427, 2005.
Reid, I. M. and Woithe, J. M.: The variability of the $558 \mathrm{~nm}$ OI airglow intensity measured over Adelaide, Australia, Adv. Space Res., 39, 1237-1247, doi:10.1016/j.asr.2007.01.061, 2007.

Reid, I. M., Holdsworth, D. A., Morris, R. J., Murphy, D. J., and Vincent, R. A.: Meteor observations using the Davis mesospherestratosphere-troposphere radar, J. Geophys. Res., 111, A05305, doi:10.1029/2005JA011443, 2006.

Reid, I. M., Spargo, A. J., and Woithe, J. M.: Seasonal variations of the nighttime $\mathrm{O}\left({ }^{1} \mathrm{~S}\right)$ and $\mathrm{OH}(8-3)$ airglow intensity at Adelaide, Australia, J. Geophys. Res.-Atmos., 119, 6991-7013, doi:10.1002/2013JD020906, 2014.

Reisin, E. R., Scheer, J., Dyrland, M. E., Sigernes, F., Deehr, C. S., Schmidt, C., Höppner, K., Bittner, M., Ammosov, P P., Gavrilyeva, G. A., Stegman, J., Perminov, V. I., Semenov, A. I., Knieling, P., Koppmann, R., Shiokawa, K., Lowe, R. P., López-González, M. J., Rodríguez, E., Zhao, Y., Taylor, M. J., Buriti, R. A., Espy, P. J., French, W. J. R., Eichmann, K.-U., Burrows, J. P., and von Savigny, C.: Traveling planetary wave activity from mesopause region airglow temperatures determined by the Network for the Detection of Mesospheric Change (NDMC), J. Atmos. Sol.-Terr. Phy., 119, 71-82, doi:10.1016/j.jastp.2014.07.002, 2014.

Remsberg, E., Lingenfelser, G., Harvey, V. L., Grose, W., Russell III, J., Mlynczak, M., Gordley, L., and Marshall, B. T.: On the verification of the quality of SABER temperature, geopotential height, and wind fields by comparison with Met Office assimilated analyses, J. Geophys. Res., 108, 4628, doi:10.1029/2003JD003720, 2003.

Roble, R. G. and Ridley E. C.: A thermosphere-ionospheremesosphere electrodynamics general circulation model (TIMEGCM): Equinox solar cycle minimum simulations $(30-500 \mathrm{~km})$, Geophys. Res. Lett., 21, 417-420, doi:10.1029/93GL03391, 1994.

Schwartz, M. J., Lambert, A., Manney, G. L., Read, W. G., Livesey, N. J., Froidevaux, L., Ao, C. O., Bernath, P. F., Boone, C. D., Cofield, R. E., Daffer, W. H., Drouin, B. J., Fetzer, E. J., Fuller, R. A., Jarnot, R. F., Jiang, J. H., Jiang, Y. B., Knosp, B. W., Krueger, K., Li, J.-L. F., Mlynczak, M. G., Pawson, S., Russell III, J. M., Santee, M. L., Snyder, W. V., Stek, P. C., Thurstans, R. P., Tompkins, A. M., Wagner, P. A., Walker, K. A., Waters, J. W., and Wu, D. L.: Validation of the Aura Microwave Limb Sounder temperature and geopotential height measurements, J. Geophys. Res., 113, D15S11, doi:10.1029/2007JD008783, 2008.

Semenov, A. I., Shefov, N. N., and Medvedeva, I. V.: Longitudinal variations in the hydroxyl emission: 1 . Temperature, J. Geomagn. Aero., 53, 492-501, doi:10.1134/S0016793213040129, 2013.

She, C. Y. and Lowe, R. P.: Seasonal temperature variations in the mesopause region at mid-latitude: comparison of lidar and hydroxyl rotational temperatures using WINDII/UARS OH Height profiles, J. Atmos. Sol.-Terr. Phys., 60, 1573-1583, doi:10.1016/S1364-6826(98)00082-0, 1998.

Shepherd, M. G., Evans, W. F. J., Hernandez, G., Offermann, D., and Takahashi, H.: Global variability of mesospheric temperature: Mean temperature field, J. Geophys. Res., 109, D24117, doi:10.1029/2004JD005054, 2004.

Shepherd, G. G., Cho, Y.-M., and Liu, G.: Correlations of mesospheric variability and their relation to the large-scale circulation during polar winter, J. Atmos. Sol.-Terr. Phy., 69, 2279-2291, doi:10.1016/j.jastp.2007.06.007, 2007. 
Sivjee, G. G. and Shen, D.: Auroral optical emissions during the solar magnetic cloud event of October 1995, J. Geophys. Res., 102, 7431-7437, doi:10.1029/97JA00195, 1997.

Smith, S. M: Seasonal variations in the correlation of mesospheric $\mathrm{OH}$ temperature and radiance at midlatitudes, J. Geophys. Res., 117, A10308, doi:10.1029/2012JA017884, 2012.

Sonnemann, G. R., Hartogh, P., Berger, U., and Grygalashvyly, M.: Hydroxyl layer: trend of number density and intra-annual variability, Ann. Geophys., 33, 749-767, doi:10.5194/angeo-33-7492015, 2015.

Torrence, C. and Compo, G. P.: A practical guide to wavelet analysis, B. Am. Meteorol. Soc., 79, 61-78, doi:10.1175/15200477(1998)079<0061:APGTWA>2.0.CO;2, 1998.

Woithe, J. M.: Optical studies of the mesospheric region, $\mathrm{PhD}$ Thesis, University of Adelaide, available at: http://hdl.handle.net/ 2440/37859 (last access: January 2016), 2000.

Xu, J., Smith, A. K., Yuan, W., Liu, H.-L., Wu, Q., Mlynczak, M. G., and Russell III, J. M.: Global structure and long-term variations of zonal mean temperature observed by TIMED/SABER, J. Geophys. Res., 112, D24106, doi:10.1029/2007JD008546, 2007.

Xu, J., Smith, A. K., Liu, H.-L., Yuan, W., Wu, Q., Jiang, G., Mlynczak, M. G., Russell III, J. M., and Franke, S. J.: Seasonal and quasi-biennial variations in the migrating diurnal tide observed by Thermosphere, Ionosphere, Mesosphere, Energetics and Dynamics (TIMED), J. Geophys. Res., 114, D13107, doi:10.1029/2008JD011298, 2009.

Xu, J., Smith, A. K., Jiang, G., Gao, H., Wei, Y., Mlynczak, M. G., and Russell III, J. M.: Strong longitudinal variations in the $\mathrm{OH}$ nightglow, Geophys. Res. Lett., 37, L21801, doi:10.1029/2010GL043972, 2010.
Xu, J., Gao, H., Smith, A. K., and Zhu, Y.: Using TIMED/SABER nightglow observations to investigate hydroxyl emission mechanisms in the mesopause region, J. Geophys. Res., 117, D02301, doi:10.1029/2011JD016342, 2012.

Younger, J. P., Lee, C. S., Reid, I. M., Vincent, R. A., Kim, Y. H., and Murphy, D. J.: The effects of deionization processes on meteor radar diffusion coefficients below $90 \mathrm{~km}$, J. Geophys. Res.Atmos., 119, 10027-10043, doi:10.1002/2014JD021787, 2014.

Younger, J. P., Reid, I. M., Vincent, R. A., and Murphy, D. J.: A method for estimating the height of a mesospheric density level using meteor radar, Geophys. Res. Lett., 42, 6106-6111, doi:10.1002/2015GL065066, 2015.

Zhao, Y., Taylor, M. J., and Chu, X.: Comparison of simultaneous $\mathrm{Na}$ lidar and mesospheric nightglow temperature measurements and the effects of tides on the emission layer heights, J. Geophys. Res., 110, D09S07, doi:10.1029/2004JD005115, 2005.

Zhang, Y., Sheng, Z., Shi, H., Zhou, S., Shi, W., Du, H., and Fan, Z.: Properties of the Long-Term Oscillations in the Middle Atmosphere Based on Observations from TIMED/SABER Instrument and FPI over Kelan, Atmosphere, 8, 7, doi:10.3390/atmos8010007, 2017.

Zhu, Y., Kaufmann, M., Ern, M., and Riese, M.: Nighttime atomic oxygen in the mesopause region retrieved from SCIA$\mathrm{MACHY} O\left({ }^{1} \mathrm{~S}\right)$ green line measurements and its response to solar cycle variation, J. Geophys. Res.-Space, 120, 9057-9073, doi:10.1002/2015JA021405, 2015. 